\title{
O ESTUDO DE PROCESSOS GEOMORFOLÓGICOS E A INTERPRETAÇÃO DOS DEPÓSITOS QUATERNÁRIOS*
}

\author{
Jan DE PLOEY**
}

\section{Caros Colegas e Amigos}

O convite da Associação Brasileira de Estudos do Quaternário para proferir esta conferência constitui para mim uma experiência interessante, uma vez que há quase vinte anos não me dedico mais, diretamente, às pesquisas sobre o Quaternário. Proporcionou-me, ainda, a oportunidade de tentar estabelecer uma ponte entre os estudos atuais sobre processos geomorfológicos e os problemas encontrados pelos quaternaristas nas regiões tropicais, mais particularmente no Brasil. Limitar-me-ei essencialmente à erosão continental e farei referência a observações de campo feitas por mim na África e aqui no Brasil.

Uma parte importante das pesquisas sobre o Quaternário é consagrada aos depósitos correlativos das vertentes. Trata-se agora de saber como as interpretações podem ser precisadas ou reorientadas em função do progresso dos conhecimentos sobre processos de vertente: movimentos de massa e erosão pluvial. Podemos considerar igualmente a ação dos rios e, finalmente, os balanços morfogenéticos, tendo-se em conta as possíveis velocidades de alteração e denudação.

Consideraremos paisagens características tanto da América do Sul como da África; por exemplo, planaltos précambrianos e paleozóicos, mais ou menos dissecados, cadeias montanhosas ou regiões de colinas, freqüentemente formadas sobre rochas duras, cristalinas ou sedimentares. Em nossas discussões manipularemos uma unidade de tempo geológico $\Delta t$, com duração de 100.000 anos.
Revisaremos uma secção subcontinental que atravessa a floresta tropical, diferentes tipos de savanas e paisagens estépicas e semi-áridas.

Deve-se lembrar que, pelo menos na Europa, os quaternaristas têm mostrado uma tendência a se interessar, cada vez mais, pelos problemas puramente estratigráficos e cronológicos. Encontramonos, portanto, numa situação em que a interpretação da dinâmica sedimentológica dos depósitos quaternários ainda não leva em conta os recentes progressos da geomorfologia: aqui existe uma lacuna que merece atenção. Os geomorfólogos têm ainda se interessado cada vez mais por problemas de aplicação, relacionados à hidrologia de superfície, à conservação dos solos e ao planejamento agrário. Entretanto, uma boa interpretação dos depósitos quaternários não pode prescindir do estudo de processos. Neste ponto, gostaria de discutir um exemplo por mim estudado na África Central, há quase vinte anos, quando trabalhava em Kinshasa (Zaire).

A região de Kinshasa é areno-síltica, desenvolvida sobre areias do Sistema do Kalahari, uma unidade neógena que recobre parte do Zaire e certos planaltos do nordeste de Angola e oeste de Zâmbia. A vegetação atual é freqüentemente constituída por savana herbácea subestépica - considerada pelos botânicos como de origem secundária e antrópica -

\footnotetext{
* Conferência proferida no Instituto Geológico-SAA sob patrocínio da Associação Brasileira de Estudos do Quaternário (ABEQUA) a 2 de agosto de 1985. Tradução de May Christine MODENESI - Instituto Geológico - Caixa Postal 8.772 - 01000 - São Paulo, SP, Brasil.

**Professor Titular da Universidade Católica de Leuven, criador e Diretor do Laboratório de Geomorfologia Experimental da mesma Universidade, Secretário da "Comissão de Experimentos de Campo em Geomorfologia" da União Geográfica Internacional e Membro da "Comissão de Erosão e Conservação do Solo" da Comunidade Européia. Laboratorium voor Geomorfologie, Instituut voor Aardwetenschappen, Redingenstraat 16 bis, B-3000, Leuven, Belgium.
} 
que substituiu as florestas virgens originais. Em 1962 pré-historiadores pediram-me para interpretar as duas unidades quaternárias arenosas da planície de Kinshasa, que incluem uma série de artefatos da Idade da Pedra: (1) unidade superior com menos de 5.000 anos BP e (2) unidade inferior correspondente a uma parte do Pleistoceno Superior; esta última é caracterizada por seleção longitudinal, a partir de colinas inteiramente constituídas de areias sílticas do Sistema do Kalahari. Durante quatro anos estudamos a erosão pluvial na savana herbácea atual, utilizando traçadores radioativos $\mathrm{Sc}^{46}$. As conclusões destes estudos foram claras:

- Atualmente, o escoamento superficial dominante é de tipo descontínuo, portanto, não existe escoamento em lençol ("sheetwash") poderoso, capaz de depositar colúvios selecionados ao pé das colinas.

- Assim que os rasos solos humíferos atuais são destruídos, a erosão pluvial torna-se muito brutal.

Desta forma, o estudo dos processos ajudou a interpretar as duas unidades quaternárias consideradas. A unidade inferior, com seus depósitos selecionados, representa colúvios formados num verdadeiro quadro paleogeográfico estépico e semi-árido e indica que, certamente, a parte ocidental da bacia congolesa conheceu um paleoclima semi-árido durante a última glaciação, digamos entre 30.000 e 5.000 anos BP. Aliás, isto é igualmente verdadeiro para os planaltos orientais da América do Sul. Mais tarde, interpretamos certas linhas de seixos em função deste mesmo paleoclima semiárido, que permitia uma forte e ampla erosão pluvial.

Passemos agora aos fenômenos de movimentos de massa, enquanto analisamos diapositivos mostrando perfis com linhas de seixos, também conhecidos no Brasil. Sob as linhas de seixos observam-se freqüentemente veios de quartzo, ou outros elementos, encurvados em direção ao sopé da vertente. Estes fenômenos são atribuídos aos efeitos do rastejo ("soil creep"). Nas regiões úmidas temperadas, dispomos agora de medidas de velocidade do rastejo (Jahn, Young, Anderson e outros) que indicam um movimento da ordem de milímetros ou centímetros por ano. Com mais razão deve-se admitir que as velocidades do rastejo sejam de mesma ordem nas regiões tropicais permanentemente úmidas. Isto significa que, considerando-se unidades de tempo geológico $\Delta \mathrm{t}$ de 100.000 anos, o rastejo constitui um movimento relativamente importante. Durante um tal período, o deslocamento global dos materiais dos solos pode variar entre 100 metros e 1 quilômetro, ou mais. A este propósito, são surpreendentes as medidas feitas em Ruanda, na África Central, pelo Dr. J. Moeyersons, que há anos segue de perto os movimentos de massa em processo numa colina argilosa deste pequeno país africano. Com o auxílio de estacas ("Youngpits") e de outras técnicas similares, ele mede o rastejo e os escorregamentos superficiais, muito ativos sobre essas colinas convexas, registrando velocidades médias anuais da ordem de centímetros ou decímetros! Como conclui o Dr. Moeyersons, a denudação das colinas é, em grande parte, comandada pelo rastejo, fato não inteiramente explicado pela mecânica clássica dos solos. Cálculos baseados num período $\Delta \mathrm{t}$ de 100.000 anos são suficientes para demonstrar que estas colinas podem "desaparecer" pelo rastejo. Note-se que o rastejo combinase com planos de cizalhamento, sem que se produzam rupturas brutais.

No ano passado visitamos, com o Eng. ${ }^{\circ}$ Charles Bonnard, da Escola Federal Politécnica de Lausanne, vertentes alpinas com substrato mais ou menos xistoso ou margoso, afetado por planos de escorregamento profundos. Medidas geodésicas muito precisas e sondagens examinadas com inclinômetro mostram a realidade de movimentos profundos e lentos que atingem igualmente velocidades de decímetros por ano. Nos Alpes, todas as vertentes sobre rochas pelíticas estão em movimento. Tal constatação demonstra, uma vez mais, a importância da denudação, quando se consideram efeitos integrados durante épocas do Quaternário. Com maior razão, isto deve ser verdadeiro para as regiões tropicais úmidas cobertas por mantos de alteritas argilosas.

Há alguns anos, com Olga Cruz e May Modenesi, publicamos artigos so- 
bre os problemas de escorregamentos no embasamento cristalino, nas serras do Mar (Caraguatatuba) e da Mantiqueira (Campos do Jordão). Nestas publicações discutimos a estabilidade relativa das alteritas face aos escorregamentos em prancha ("planar slides") e chegamos à conclusão de que, em períodos muito chuvosos, quando a evapotranspiração é negligenciável, a presença da floresta favorece os grandes escorregamentos. Os sistemas radiculares aumentam a condutividade hidráulica dos solos e grandes quantidades de água são armazenadas no manto de alteração. A seco, o ângulo de atrito $\gamma^{\prime} \mathrm{r}$ pode ser da ordem de $40^{\circ}$. $50^{\circ}$, mas vertentes de morros com $20^{\circ}$ $30^{\circ}$ tornam-se críticas em períodos muito úmidos. Com efeito, aplica-se aqui a equação:

\section{$\mathrm{S}_{\mathrm{cr}}=\operatorname{arctg}(1-\mathrm{m} . \mathrm{Pw} / \mathrm{Pn}) \operatorname{tg} \gamma^{\prime} \mathrm{r}$}

onde, $\mathrm{Scr}=$ inclinação crítica em graus; $m=0$ ou $m=1$, conforme a posição do lençol d'água, ausente ou embebendo todo o manto de alteração; $\mathrm{Pw}=$ peso unitário da água; $\mathrm{Pn}=$ peso unitário do solo úmido embebido d'água; $\gamma$ 'r $=$ ângulo de atrito residual de materiais não consolidados. Portanto, nota-se que $\mathrm{S}_{\mathrm{cr}}$ tem um valor mínimo quando $\mathrm{m}=1$, durante um período muito chuvoso.

Acreditamos que a floresta pôde, portanto, ativar os movimentos de massa durante os paleoclimas úmidos quaternários. Esta tese é sustentada por observações de Usselmann, Thomas e So, respectivamente nos Andes, em Papua - Nova Guiné e em Hong Kong. O corolário leva novamente a supor uma maior estabilidade das vertentes durante os períodos mais secos, pelo menos no que concerne ao rastejo e aos grandes movimentos de massa. Notemos que Selby, na Nova Zelândia, cita igualmente velocidades de rastejo, profundo e contínuo, da ordem de 10 a $20 \mathrm{~cm} /$ ano. Podemos agora adiantar alguns cálculos a respeito dos efeitos morfogênicos deste rastejo, em vertentes com um manto de alteração de $10 \mathrm{~m}$ de espessura, por exemplo. Suponhamos velocidades de rastejo de $10 \mathrm{~cm} /$ ano e de $20 \mathrm{~cm} /$ ano numa vertente com $1 \mathrm{~km}$ de comprimento. Todo o regolito será evacuado entre
10.000 e 5.000 anos! Se a velocidade de alteração se mantiver em equilíbrio com a velocidade de denudação $\Delta \mathrm{D} / \Delta \mathrm{t}$, o recuo das vertentes irá variar de 1 a $2 \mathrm{~mm} /$ ano. Realizar-se-á então um recuo global de 100 a $200 \mathrm{~m}$ em 100.000 anos. O rastejo profundo torna-se assim, à escala do tempo quaternário, um macroprocesso. Mas a evolução das vertentes dos morros poderá se tornar muito mais rápida se durante períodos úmidos, com encostas recobertas por florestas, ocorrerem escorregamentos em prancha.

Assim, não se pode escapar da discussão das velocidades de alteração $\Delta \mathrm{A} / \Delta \mathrm{t}$. Com efeito, depois de escorregamentos catastróficos o substrato rochoso aflora. A partir deste momento, a velocidade de denudação $\Delta \mathrm{D} / \Delta \mathrm{t}$ dependerá da velocidade da decomposição da rocha e, portanto, entre outros fatores, da velocidade colonizadora da vegetação. Em Caraguatatuba, após os acontecimentos catastróficos de 1967 , esta colonização parece progredir com bastante rapidez. Portanto, volta-se à discussão $\Delta \mathrm{A} / \Delta \mathrm{t} \gtreqless$ $\Delta \mathrm{D} / \Delta \mathrm{t}$. Os dados que encontramos na literatura sobre as velocidades de alteração $\Delta \mathrm{A} / \Delta \mathrm{t}$ são muito pobres. No desenvolvimento de seus modelos Armstrong e Ahnert supõem que

$$
W=W_{\text {pot }} e^{-k d . d}
$$

$\mathrm{W}=$ velocidade de alteração

$\mathrm{W}_{\text {pot }}=$ velocidade de alteração máxima

$\mathrm{Kd}=$ constante de campo

$\mathrm{d}=$ espessura do regolito

As cifras adiantadas pelos diferentes autores são variáveis mas jamais superam $1 \mathrm{~mm}$ /ano (Mann e Ollier, Birot). Birot cita avaliações de Gac, Pinta e outros autores franceses que não ultrapassam $0,5 \mathrm{~mm} /$ ano. Tendo-se em conta a discussão citada anteriormente, isto significa que

\section{$\Delta \mathrm{A} / \Delta \mathrm{t}<\Delta \mathrm{D} / \Delta \mathrm{t}$}

portanto, a evolução morfogênica é essencialmente controlada pela velocidade de alteração a qual, dificilmente, ultrapassaria $1 \mathrm{~mm} /$ ano. Já o rastejo profundo e contínuo poderia estar em 
equilíbrio com a velocidade de alteração. Se, por exemplo, sob floresta tropical, intervêm grandes escorregamentos em prancha, o substrato aflora e a erosão deve "esperar" o desenvolvimento inicial de um manto de alteração, segundo o valor $W_{\text {pot }}$ correspondente à velocidade de alteração potencial máxima.

Em todo caso, quando consideramos períodos unitários de 100.000 anos, é evidente que os efeitos combinados da denudação e da alteração sobre a evolução do relevo são significativos, mesmo se nos limitarmos apenas à intervenção dos processos de movimento de massa.

Igualmente, sob floresta tropical, a velocidade da denudação $\Delta \mathrm{D} / \Delta \mathrm{t}$ é aumentada pela erosão química e pela erosão pluvial. Esta última repete-se em diferentes subprocessos: erosão pelo "splash" (ação do impacto das gotas d'água sobre o solo), erosão por escoamento hipodérmico, erosão por "piping" (erosão subterrânea), escoamento superficial sobre caminhos etc. McGregor reúne dados de Rougerie, Fearnside, Leigh e outros autores. Bishop e Rougerie insistem na importância da erosão linear sob floresta tropical na África, onde até mesmo o ravinamento é ativo. Este fato é confirmado pelo estudo efetuado na floresta da Tijuca, Rio de Janeiro, por A.L. Coelho Neto da Universidade Federal do Rio de Janeiro.

Os dados reunidos por McGregor apresentam velocidades $\Delta \mathrm{D} / \Delta \mathrm{t}$ da ordem de vários milímetros por ano. Isto significa que, sem a intervenção de movimentos de massa maiores, a erosão sob floresta é importante desde que se façam, novamente, extrapolações para períodos quaternários de várias centenas de milhares de anos. Efetivamente, a velocidade de denudação pode sempre ultrapassar a velocidade de alteração.

Analisemos agora o problema das linhas de seixos à luz de novos dados experimentais, que ajudam a compreender a transportabilidade dos seixos e os efeitos da cobertura de cascalho sobre a gênese do escoamento superficial ("runoff'") e sobre a intensidade da erosão pluvial. Em primeiro lugar, devemos salientar o papel das coberturas de materiais grosseiros na intensificação do escoamento superficial, pois os seixos con- tribuem para impermeabilizar o solo. Por outro lado, se a densidade da cobertura de seixos for suficiente, este material poderá proteger a superfície do solo contra a erosão pluvial. Múltiplas experiências de laboratório demonstraram ser muito difícil realizar a evacuação de detritos grosseiros pelo escoamento nas áreas entre filetes d'água ("interrills"). Nestes locais pode ocorrer um rastejo por ação do escoamento superficial ("runoff creep") muito limitado, que desloca os seixos à distância de alguns milímetros, sobretudo em solos arenosos. Entretanto, sobre siltes coesos este transporte é extremamente difícil. Ao contrário, segundo dados experimentais obtidos pelo Dr. Poesen, seixos com diâmetro centimétrico são facilmente evacuados no interior dos filetes. Débitos unitários de 20 a $50 \mathrm{cc} / \mathrm{cm} / \mathrm{s}$ são amplamente suficientes para evacuar seixos em declives de 5 a $10 \%$. Transporte e erosão podem-se alternar. Seixos temporariamente depositados em depósitos coluviais de vertente podem ser retomados, em seguida, pelos filetes. Esta dinâmica pode explicar a gênese das linhas de seixos compostas, com vários níveis de cascalho. Ao mesmo tempo, pode ocorrer sedimentação de silte ou de areia, segundo um modelo de coluviação por nós desenvolvido recentemente:

$$
\mathrm{S}_{\mathrm{cr}}=\mathrm{A} \cdot \mathrm{c}^{0,8} / \mathrm{q}^{0,5}
$$

onde

${ }^{\mathrm{s}} \mathrm{cr}=$ inclinação crítica em que se inicia o escoamento.

$\mathrm{c}=$ carga sólida do escoamento superficial, em g/1.

$\mathrm{q}$ = débito unitário do escoamento superficial, em $\mathrm{cm}^{2} / \mathrm{s}$.

$\mathrm{A}=$ coeficiente empírico cujo valor cresce com $\overline{\mathrm{D}}$, a dimensão média dos sedimentos.

Este modelo e observações de campo indicam que o coluvionamento não se limita aos fundos de vale mas já pode começar nas porções intermediárias das vertentes, quando os valores de c ultrapassam a capacidade de transporte do escoamento superficial.

Voltemos ainda à discussão das interações entre o escoamento superficial e a 
cobertura de seixos. Um seixo com densidade $\mathrm{x}$ pode ativar a erosão numa encosta relativamente íngreme e reduzi-la em encostas de fraca declividade. Uma cobertura estépica pode ter efeitos ambivalentes similares. $O$ conceito de papel ambivalente de certos fatores geomorfológicos exige, cada vez mais, a nossa atenção. Em todo o caso, os fenômenos acima citados intervêm na interpretação dos perfis com linhas de seixos.

Torna-se agora compreensível por que a erosão das vertentes pôde alimentar em seixos os rios quaternários. Com efeito, constatamos que, por ocasião das grandes chuvas, a formação de filetes torna perfeitamente possível a evacuação de seixos.

Devemos igualmente chamar a atenção sobre as possíveis interpretações da paleo-hidrologia e paleo-hidráulica dos rios, levando em consideração as dimensões dos seixos e a declividade do curso d'água (relacionado ao terraço) S. Uma vez que os seixos são representativos para a capacidade de transporte dos cursos d'água, podemos explorar as relações conhecidas entre as dimensões $\overline{\mathrm{D}}$ dos seixos transportados e a pressão de cizalhamento das águas correntes, Tc:

$$
\bar{D}=f(T c)=f(\varrho \cdot g \cdot R \cdot S)
$$

onde

$\varrho=$ densidade da água

$\mathrm{g}=$ constante de gravidade

$\mathrm{R}=$ raio hidráulico

$\mathrm{S}=$ declividade do curso d'água

Em princípio, é portanto possível discutir o valor de $\mathbf{R}$ (aproximadamente igual à profundidade média do rio) com base em valores conhecidos de $\overline{\mathrm{D}}$ e de $\mathrm{S}$. Podemos então passar à equação de Manning para avaliar o paleodébito dos rios quaternários responsáveis pelos depósitos de terraço.

Concluímos que a erosão pluvial sob floresta nem sempre é negligenciável, ao contrário. Nos maciços montanhosos com declividades médias ou fortes somam-se, eventualmente, os ef eitos dos movimentos de massa. Se consideramos a floresta seca e as savanas é então evidente que a erosão pluvial é fortemente influenciada pelos agentes biológicos.
Antes de mais nada, a taxa de cobertura vegetal dos solos pode variar com as estações. Além disto devemos considerar a ação dos animais fuçadores, acumulando em superfície sedimentos móveis que podem ser atacados pela erosão pluvial. Mas continua difícil interpretar os paleoambientes quaternários, sobretudo no que concerne à natureza e à intensidade dos impactos biológicos sobre a erosão.

Atualmente, nas regiões de savanas degradadas por ações antrópicas observamos, com freqüência, $o$ aprofundamento dos fundos de vale por rios temporários. Durante os últimos milênios fundos de vale foram preenchidos por colúvios estratificados. No caso da Nigéria Setentrional, por nós descrito, a destruição da vegetação original e o cultivo mudaram todo o sistema hidrológico e geomorfológico; esta mudança brutal ocorreu nas últimas décadas. Na Austrália tivemos a oportunidade de observar a mesma sucessão: coluvionamentos nos fundos de vale durante os últimos milênios e aprofundamento de ravinas depois da colonização inglesa. Finalmente, as rampas de colúvio brasileiras mostram sucessões semelhantes, mas, aqui, são observados depósitos que se esparramam na base de encostas relativamente ingremes, da ordem de 8 a $10 \%$. As formações coluviais da Nigéria e da Austrália cobrem encostas mais suaves.

A discussão da gênese destes depósitos leva-nos ao modelo de coluvionamento $\mathrm{S}_{\mathrm{cr}}$ apresentado anteriormente. Note-se que tais coluvionamentos não apresentam traços de erosão linear, de ravinamentos.

No caso dos depósitos nigerianos e australianos estimamos valores de c (carga sólida) e q (débito unitário) fracos. O coluvionamento foi favorecido por uma vegetação mais densa cobrindo fundos de vale mais úmidos. Na região de Gombe, na parte centro-norte da Nigéria, a vegetação original de savana arbórea que recobria colinas de declividade fraca foi destruída há quase 50 anos, quando da introdução da cultura do algodão. A partir deste momento desenvolveram-se grandes ravinas que se transformaram em rios temporários, como por exemplo o rio Nono da bacia do Gongola. Antes 
da grande colonização agrícola, escoamento e coluvionamento eram fracos, por duas razões essenciais: (1) a proteção oferecida pela cobertura vegetal e (2) a grande capacidade de infiltração dos solos de savana, dotados de uma certa estrutura em grumos e consideravelmente remanejados pela fauna do solo. Após a implantação do algodão, a degradação estrutural dos solos e o aumento dos coeficientes de escoamento provocaram a incisão das ravinas e a formação de rios temporários cujos leitos apresentam, com freqüência, mais de $100 \mathrm{~m}$ de largura. Como tivemos a oportunidade de constatar nas proximidades de Armidale, uma evolução análoga marcou regiões dos planaltos de Nova Gales do Sul, na Austrália. Solos desenvolvidos sobre embasamento cristalino e originalmente recobertos por Eucalyptus foram desmatados durante o século passado, quando da colonização britânica. Nesta região, como na Nigéria, camadas de colúvios, às vezes humíferos, ocorrem dissecadas por ravinamentos sub-recentes; é interessante notar o aspecto contínuo destes colúvios, jamais interrompidos por estratificações oblíquas ou cruzadas capazes de indicar um antigo sistema de erosão linear.

Mas, nas regiões brasileiras onde se encontram rampas de colúvio na base de vertentes relativamente íngremes, a situação é diferente. Muitos depósitos de rampas de colúvio, com grandes valores de c, parecem resultar de uma sedimentação a partir de águas muito lamacentas. Como sabemos, o escoamento superficial do tipo corrida de lama ("mudflow") pode evacuar concentrações c da ordem de 300 a $500 \mathrm{~g} / 1$. As camadas das rampas de colúvio são, freqüentemente, mal calibradas. Provavelmente tais coluvionamentos sucediam a escorregamentos ou ravinamentos que atacavam as vertentes dos vales. A sedimentação era manifestamente brutal, resultado de uma deposição abrupta de todas as frações granulométricas.

\section{CONCLUSÕES FINAIS}

Foram aqui discutidos processos de vertente atuando em regiões tropicais montanhosas ou colinosas durante o Quaternário. A evolução destes relevos parece ter sido controlada pela velocidade de alteração $\Delta \mathrm{A} / \Delta \mathrm{t}$ e, portanto, pelo desenvolvimento dos regolitos. Mas é preciso insistir no fato de que a literatura oferece relativamente poucas informações sobre as medidas de velocidade de alteração. Informações sobre as velocidades de denudação são muito mais abundantes.

Não nos parece que a velocidade mínima de denudação $\Delta \mathrm{D} / \Delta \mathrm{t}$ ocorra em meio florestal, onde a erosão pluvial pode ser real e onde se manifestam movimentos de massa muito violentos. Acreditamos que durante o Quaternário a erosão foi mínima em certos tipos de savana, onde os solos se encontravam bastante protegidos pela vegetação herbácea.

Finalmente, foram discutidas certas formações coluviais quaternárias, à luz de um novo modelo de coluvionamento.

\section{AGRADECIMENTOS}

Agradeço à Dra. May C. Modenesi a tradução do texto original.

\section{REFERÊNCIAS BIBLIOGRÁFICAS}

AHNERT, F. 1970 A comparison of theoretical slope models with slopes in the field. Zeitschrift für Geomorphologie, Berlin, Supplementband 9 p. 88-101.

ARMSTRONG; A.C. 1980 Soils and slopes in a humid temperate environment: a simulation study. Catena, Giesseh, Germany, 7(4): 327 338 .
BIROT, P. 1981 Les processus d'érosion à la surface des continents. Paris, Masson. 605p.

BONNARD, C. 1983 Determination of slow landslide activity by multidisciplinary measurement techniques. In: International Symposium on Field Measurements in Geomechanics, Zurich, September 5-8. 
BONNARD, C. 1985 Projet d'École. Détection et utilisation des terrains instables. Rapport final. Lausanne.

COELHO NETTO, A.L. 1985 Surface hydrology and soil erosion in a tropical mountainous rainforest drainage basin, Rio de Janeiro.

LEIGH, C.H. 1978 Slope hydrology and denudation in the Pasoh forest reserve. Malayan $\mathrm{Na}$ ture Journal, 30:179-197.

MCGREGOR, D.F.M. 1980 An investigation of soil erosion in the Colombian rainforest zone. Catena, 7(4):265-273.

MANN, A.W. \& OLLIER, C.D. 1985 Chemical diffusion and ferricrete formation. In: JUNGERIUS, Peter D., ed. Soils and geomorphology. Giessen, Germany, Catena Verlag. p. 151-157. (Catena Supplement, 6)

MOEYERSONS, J. 1981 Slumping and planar sliding on hill-slopes in Rwanda. Earth Surface Processes and Landforms, 6:265-274.

1981 Les transports de masse: leur nature, leur importance et leur effets morphologiques dans la région de Butare, Rwanda. Museum Royal African Central Tervuren, Rapport Annual 1980, 55/65:55-65.

MOUSINHO DE MEIS, M.R. \& MONTEIRO, A.M. 1979 Upper Quaternary rampas; Doce river valley, Southeastern Brazilian plateau. Zeitschrift für Geomorphologie, N.F., Berlin, 23(2): 132-151.

NOTEN, F. Van \& PLOEY, J. de. 1977 Quaternary research in Northeastern Nigeria. Koninklijk Museum voor Midden-Afrika, Tervuren, België. Annalen, reeks IN-8, Menselijke Wetenschappen, 92.
PLOEY, J. de. 1969 L'érosion pluviale: expériences à l'aide de sables traceurs et bilans morphogéniques. Acta Geographica Lovaniensia, 7:1-28.

1982 Concerning factors. In: IGU Latin American Regional Conference. vol. 2 Symposia and round tables p. 317-322.

1984 Hydraulics of runoff and loess loam deposition. Earth Surfaces Processes and landforms, Chichester, New York, 9:533-539.

\& CRUZ, O. 1979 Landslides in the Serra do Mar, Brazil. Catena, Giessen, Germany, 6(2): $111-122$.

; CRUZ, O.; MODENESI, M.C. 1983

Résistances au cisaillement et conditions de glissements de terrain à Caraguatatuba et à Campos do Jordão (état de São Paulo). In: COLÓQUIO INTERDISCIPLINAR FRANCO-BRASILEIRO; ESTUDO E CARTOGRAFIA DE FORMAÇÕES SUPERFICIAIS E SUAS APLICAÇÕES EM REGIÕES TROPICAIS, São Paulo, 1978. Comunicações e debates. São Paulo, Universidade, Faculdade de Filosofia, Letras e Ciências Humanas. Departamento de Geografia. v. 1 p. 393-402.

ROUGERIE, G. 1960 Le façonnement actuel des modelés en Côte d'Ivoire forestière. Mémoire IFAN, 58. 541 p.

THOMAS, M.F. 1974 Tropical geomorphology. London, Macmillan, 332p.

USSELMANN, P. 1968 Revue de Géomorphologie Dynamique, Paris, 18(4):1-15. 